\title{
Stimulus duration and conditioned reinforcing value measured by a learning-tests procedure
}

\author{
SUZETTE L. ASTLEY and CHARLES C. PERKINS \\ Kansas State University, Manhattan, Kansas
}

\begin{abstract}
The relationship between the duration of stimuli and their conditioned reinforcing effect was investigated using a learning-tests procedure. In Experiment 1, stimuli were the same duration on training (stimulus $\rightarrow$ reward) and test (choice response $\rightarrow$ stimulus). Ten- and 30 -sec stimuli provided effective differential conditioned reinforcement but 3-sec stimuli did not. In Experiment 2, different pigeons had each combination of the 3- and 30-sec stimuli on training and test trials. Evidence of conditioned reinforcement was obtained only for the birds with 30 -sec stimuli on both training and test. The results were interpreted as indicating that stimuli become effective conditioned reinforcers on test trials only when their duration exceeds the duration of differential short-term memory cues resulting from a difference in the events that precede them on training and test trials.
\end{abstract}

In a recent report of an experiment on delayed reward learning in pigeons, Winter and Perkins (1982) obtained results which they interpreted as indicating that, in their procedure, 10-sec stimuli provided differential conditioned reinforcing effects but .33 -sec stimuli had no differential conditioned reinforcing effect. In their Experiment 1 , a sequence of three successive stimuli were presented during the 60 -sec interval between the choice response and reward or nonreward. The sequence of events that followed the rewarded response $(\mathrm{R}+)$ was $\mathrm{A} \rightarrow \mathrm{C} \rightarrow \mathrm{B} \rightarrow$ food, and the sequence that followed the nonrewarded choice response $(R-)$ was $B \rightarrow D \rightarrow A$ food (no food), where A, B, C, and D represented different stimuli (houselights). The only difference between their two groups was the duration of the component stimuli. For Group 10, the durations were $10 \mathrm{sec}$ for Stimuli $\mathrm{A}$ and $B$ and $40 \mathrm{sec}$ for stimuli C and D. For Group .33, the duration of $A$ and $B$ was $.33 \mathrm{sec}$ and for $C$ and $D$, $59.3 \mathrm{sec}$. Group 10 initially acquired a marked preference for R-. Apparently, Stimulus B, which both immediately followed $\mathrm{R}-$ and preceded food on $\mathrm{R}+$ trials, had acquired greater conditioned reinforcing value than Stimulus A, which immediately followed $\mathrm{R}+$ and never immediately preceded food. After further training, these birds no longer showed this preference and switched their choice to the response followed by the delayed food reward. The birds in Group .33 did not show a preference for the nonrewarded response at any time but rapidly acquired the rewarded response, indicating that the differential conditioned reinforcing value presumably acquired by the .33 -sec Stimulus A preceding reward did not generalize to Stimulus A when it followed $\mathrm{R}-$.

Experiment 1 was conducted in partial fulfillment of the requirements for S.L.A.'s MA degree. Reprints may be obtained from C. C. Perkins, Department of Psychology, Kansas State University, Manhattan, KS 66506, or from S. L. Astley, Cornell College, Mt. Vernon, IA 52314.

Article accepted by previous editor, Robert C. Bolles.
The Winter and Perkins results seem to indicate that in a learning-tests procedure (Wike, 1966), stimuli would be shown to have conditioned reinforcing value only if their duration on both training and test trials exceeded some value. The results of their Experiment 2 (not described here) suggested that this value might be about $30 \mathrm{sec}$ for pigeons. The experiments described here were designed to determine if this relationship between stimulus duration and its reinforcing value would be obtained in a learning-tests procedure.

\section{EXPERIMENT 1}

Experiment 1 is an investigation of the relationship between the duration of stimuli and the differential conditioned reinforcing value they exhibit. We employed a learning-tests procedure in which one stimulus $\left(\mathbf{S}^{\mathbf{r}}+\right)$ was followed by food on $90 \%$ of the training trials and another $\left(\mathrm{S}^{\mathrm{r}}-\right.$ ) was followed by food on only $10 \%$. On independent test trials, choice stimuli were presented. Pecks to one choice stimulus produced $S^{r}+$ and pecks to the other produced $S^{\mathbf{r}}-$. There were three groups, which differed only in the durations of $S^{r}+$ and $S^{r}-$. Throughout the experiment, every presentation of these stimuli lasted 3,10 , and $30 \mathrm{sec}$ for Groups 3, 10, and 30, respectively.

\section{Method}

Subjects. Twelve experimentally naive adult pigeons served as subjects. They were maintained at $75 \%$ of their free-feeding weights and kept under continuous illumination in individual cages containing grit and water. Data from additional birds were discarded due to apparatus malfunction. The discarded data did not differ substantially from those reported.

Apparatus. Daily sessions were conducted in four two-key pigeon chambers located in sound-attenuating housings. The inside dimensions of the chambers were about $32 \times 23 \times 25 \mathrm{~cm}$. The response keys were located $20 \mathrm{~cm}$ above the floor, $5.8 \mathrm{~cm}$ apart from center to center, and equidistant from the midline of the intelligence panel. Stimuli were projected on the keys by miniprojectors behind the intelligence panel. When a key was struck by a force of at least 
$.06 \mathrm{~N}$, it registered a peck and produced a feedback click. An opening providing access to the Lehigh Valley grain feeder filled with a 50-50 mixture of wheat and milo was located beneath and equidistant from the two keys. The feeder was illuminated during food presentation. A white 3-W houselight enclosed by an inverted Styrofoam cup was located $19 \mathrm{~cm}$ above the floor in the middle of the wall opposite the intelligence panel. Extraneous sounds were masked by a ventilation fan and a speaker transmitting white noise. Both were located behind the intelligence panel. Events were programmed by electromechanical equipment located in an adjoining room.

Procedure. Color of $\mathrm{S}^{\mathrm{r}}+$ and the side on which it appeared following choice were both fully counterbalanced across birds. Nevertheless, to simplify the exposition, training will be described for only one of the four counterbalanced conditions within each group.

All pigeons were first trained to eat promptly from the food magazine whenever food was presented. During subsequent pretraining sessions, the pigeons were exposed to 10 presentations each of red and green stimuli on each key, making for a total of 40 trials. Food followed $90 \%$ of the presentations of $S^{r}+(r e d)$ and $10 \%$ of the presentations of $\mathbf{S}^{r}-$ (green) on each key. The sequence of trials was random within blocks and thus unpredictable. Each pigeon was advanced to Phase 1 on the session following that on which it attained an average rate of at least 9.6 pecks/min during red and green combined.

During Phase 1 , the response-independent training trials continued as in pretraining, but 10 pairs of one test and one forced trial were interspersed among them. The pairs of test-forced trials were as depicted in Figure 1. Test trials began with both keys illuminated white. If the right key was pecked, it immediately became green and the other key dark. If the left key was pecked, it became red and the right key dark. Test trials were followed by food on a randomly selected $50 \%$ of the trials in each session. After the next intertrial interval, a forced trial began with white illumination of the key that had not been pecked on the preceding test trial. When pecked, this white key turned green when it was on the right and red when it was on the left. Food presentations followed a forced trial if and only if food had followed the preceding test trial. Note that red and green were each followed by food on $50 \%$ of these test trials. The houselight was illuminated except during food presentation.

Phase 2 was the same as Phase 1, except that the color-side pairing on test and forced trials was reversed. That is, red now followed a peck to the right and green followed a peck to the left on all test and forced trials.

There were two predetermined criteria for completion of Phases 1 and 2. These phases were terminated as soon as: (1) a bird chose

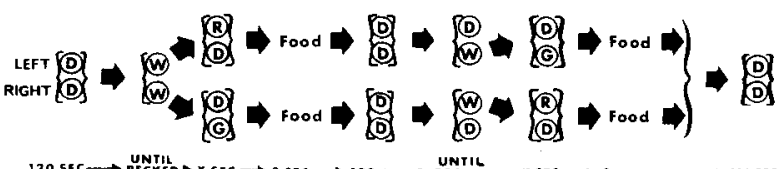

Figure 1. Sequence of events on a free-forced pair of responsedependent trials in Experiment 1 . The choice trial was initiated by transillumination of both keys by a white light (W). A peck to one key (e.g., left) was followed by a change in that key to the color appropriate for that side, for example, red (R) in the figure, and darkened the other key. The duration of the red and green $(G)$ was 3, 10 , or $30 \mathrm{sec}$ depending on group assignment. On the trial following each choice, only the key that had not been chosen on the preceding trial became white, and a response to that key was required for progression through the sequence. The figure represents a pair of food trials. Half the trial pairs were food trials; the other half were identical, except that no food was presented. During the 120sec intertrial interval, the keys were dark (D).
$\mathrm{S}^{\mathrm{r}}+$ on 19 of a possible 20 test trials in two consecutive sessions, or (2) the pigeon had completed 15 sessions of that phase.

Groups of birds differed only in the duration of the red and green stimuli. Every presentation of these stimuli was 3, 10, or $30 \mathrm{sec}$ in duration for Groups 3,10, and 30, respectively. All trials were separated by $120-\mathrm{sec}$ intertrial intervals, during which the keys were dark.

\section{Results and Discussion}

All birds required from one to five sessions of pretraining to reach a session mean of 9.6 autoshaped pecks $/ \mathrm{min}$ during $S^{r}+$ and $S^{r}-$ combined. The median number of sessions required was two. There were no systematic group differences in amount of pretraining.

Preference measures. Figure 2 shows the mean percent choice of $S^{r}+$ for each group in each session of Phases 1 and 2 . Each bird that met the criterion, 19 of 20 choices of $\mathbf{S}^{\mathrm{r}}+$ on two successive sessions before the 15-session limit, was assigned a score of $100 \%$ choice of $S^{r}+$ for each subsequent session of that phase. This may have slightly increased the height of the curves during the latter sessions of each phase for Groups 10 and 30, but with the rigorous criterion used, any such effect would be too small to affect our conclusions. As can be seen in Figure 2, Groups 10 and 30 chose the response followed by $\mathrm{S}^{\mathrm{r}}+$ between $80 \%$ and $100 \%$ of the time by the end of each phase, and Group 3 never chose $S^{r}+$ more than $70 \%$ of the time for two consecutive sessions.

Figure 3 shows the percent choice of $S^{r}+$ on each session for individual pigeons. Examination of Figure 3 indicates that performance of Group 3 birds differed markedly from the performance of the birds in the other two groups. None of the Group 3 pigeons showed an overall preference for $S^{\mathrm{r}}+$ during both Phase 1 and Phase 2. On the other hand, with one possible exception (T14), every bird in Groups 10 and 30 showed a preference for $S^{r}+$ in each phase. Furthermore, in Groups 10 and 30 combined, five of eight birds met the choice criterion in both phases within 15 sessions. The remaining three birds in these groups met the criterion in one phase. In contrast, no bird in Group 3 met the criterion in both phases and two did not meet the criterion in either phase.

Even though examination of the results for individual birds seems to provide adequate evidence that performance of Group 3 differed reliably from the performance of the other two groups, an index of the reinforcing effect of $\mathbf{S}^{\mathrm{r}}+$ on test trials was obtained for each bird and the indices were then submitted to a Kruskal-Wallis test. The index employed was the number of choices of $S^{r}+$ on Sessions 6-15 of both phases combined. By combining the two phases, this index minimizes possible effects of side preferences. For birds that met the criterion of 19 of 20 choices of $S^{r}+$ on Session $N, 10$ choices of $S^{r}+$ were scored for each of Sessions $N+1$ to 15 of that phase. Because the same method of scoring was used for each subject, inclusion of scores of 10 choices of $S^{r}+$ on postcriterion sessions does not invalidate the rationale for use of the Kruskal-Wallis test. The overall group effect was significant $(\mathrm{H}=7.4, \mathrm{p}<.02)$. There was no overlap 


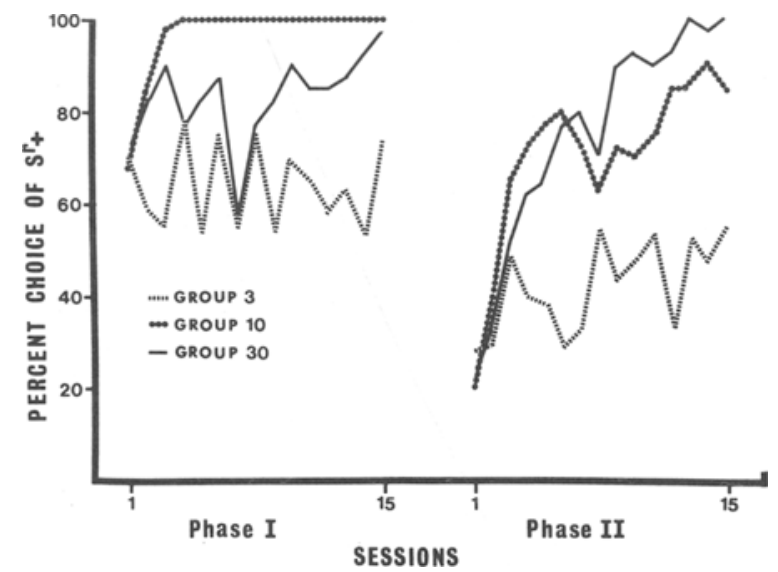

Figure 2. Mean percent choice of $\mathbf{S}^{\mathrm{r}}+$ for each group in Experiment 1 during each session of Phases 1 and 2 . Note that if a bird chose $S^{r}+$ on 19 of the 20 choice trials on two successive sessions, he was scored as choosing $S^{r}+$ on all subsequent sessions of that phase, even though his training in that phase had been terminated.

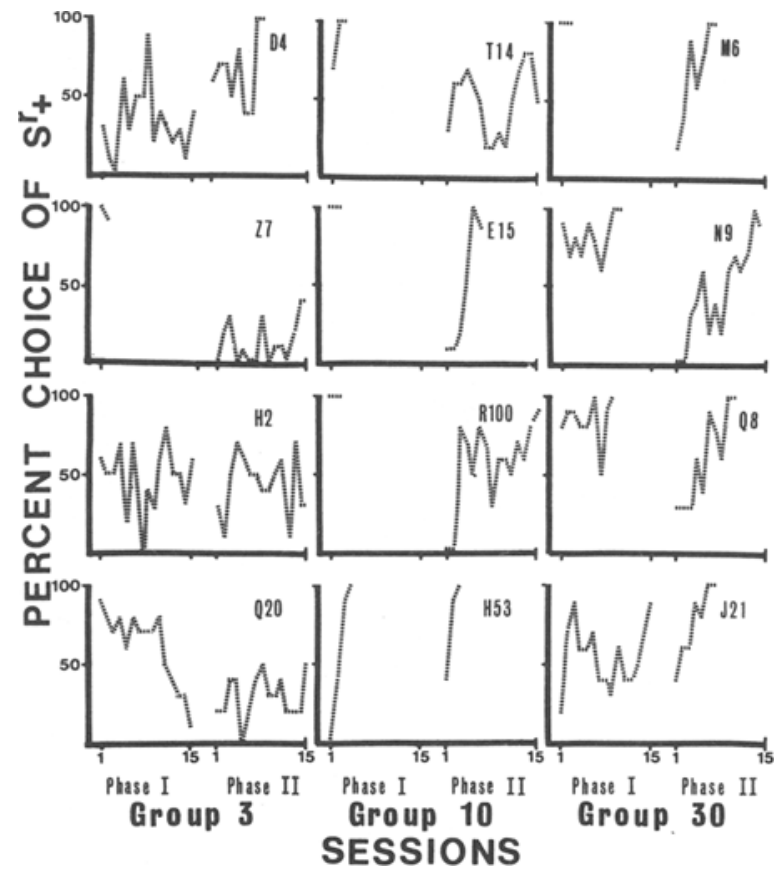

Figure 3. Percent choice of $\mathbf{S}^{\mathbf{r}}+$ on all sessions for individual subjects in Experiment 1. Each column presents results for subjects in a different group.

between the index obtained for Group 3 birds and birds in either of the other two groups (i.e., Mann-Whitney $\mathrm{U}=0, \mathrm{p}<.03$ ). The difference between indices obtained from Groups 10 and 30 was not statistically significant.

Autoshaped keypecks. Figure 4 shows the mean pecks/second during $S^{r}+$ and $S^{r}-$ for each session, starting with the first session of Phase 1. Data are presented separately for training and test trials. Note that pecks to
$S^{r}+$ and $S^{r}-$ had no effect on the environment and that they were therefore autoshaped keypecks. Two things should be noted about the way in which the data are plotted in Figure 4. First, points may be based on data from Phase 1, Phase 2, or both because ordinal number of a session was counted beginning with the first session of Phase 1 even after a bird had been reversed. It seemed appropriate to combine data from Phases 1 and 2 because the probability that food would follow $S^{r}+$ and $S^{r}-$ on both training and test trials remained the same throughout. Second, points to the right of the arrows are based on results from only three birds, those that had not yet met the criterion for termination of Phase 2. All points plotted are based on data from at least three birds.

Note that the rates of (auto)pecking are about the same to $S^{r}+$ and $S^{r}-$. Rate of autopecking during both $S^{r}+$ and $S^{\mathrm{I}}$ - was greater, the briefer these stimuli within the 330 -sec range employed. The higher rate on test than training trials probably only reflects the bird's greater proximity to the key at the onset of $S^{r}$ on test trials.

Our findings that brief (3-sec) stimuli that are differential predictors of reward on training trials do not have a differential reinforcing effect on test trials is in line with the Winter and Perkins results. The explanation of this result that we favor is that when $S^{\mathrm{r}}$ duration is $3 \mathrm{sec}$ or less, the pattern of cues just before offset of $S^{\mathbf{r}}+$ on test trials is discriminated from the pattern of cues just before offset of $S^{r}+$ on training trials and that the same is true for $\mathrm{S}^{\mathbf{r}}$. . As a result, the differential conditioned re-
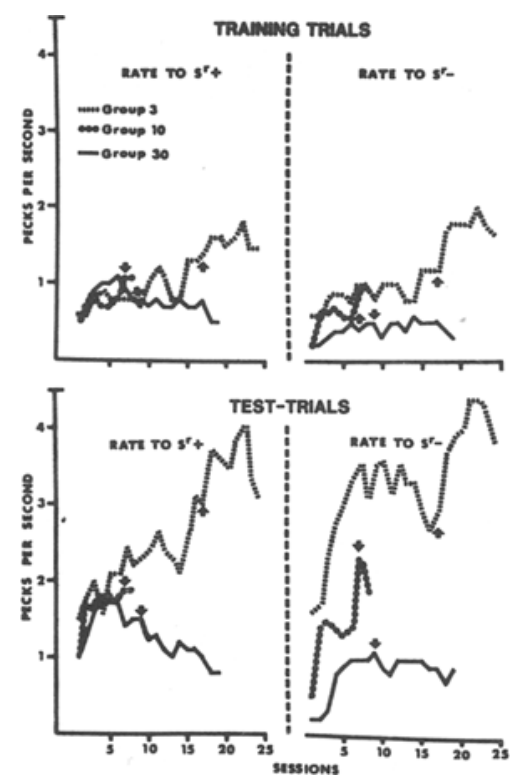

Figure 4. Mean rate of keypecking for each group in Experiment 1 during $S^{\mathrm{r}}+$ (two graphs at the left) and $\mathbf{S}^{\mathrm{r}}-$ (right). Broken lines, chain of dots, and solid lines are for Groups 3,10, and 30, respectively. The upper graphs represent rate in pecks/second on training trials; the lower graphs represent test trials (both choice and forced). Points to the right of arrows are based on results after one bird in the group had reached criterion, and therefore are only for three birds. All other points are means for all four birds in the group. 
inforcing value acquired by $S^{r}+$ and $S^{r}-$ on training trials does not generalize to test trials.

In the most comparable procedures of which we are aware, pigeons' short-term memory (STM) cues seem to provide a basis for differential responding for between 3 and $30 \mathrm{sec}$ (e.g., Grant \& Roberts, 1976; Maki, Moe, $\&$ Bierley, 1977). Conditions during the 3-sec S $S^{\mathrm{r}}$ s would therefore contain different STM cues throughout training and test trials (i.e., both choice and forced trials). As a consequence, the two types of trials would be discriminated throughout the presentation of $S^{r} s$. Therefore, the reinforcing value of red and green keylights on test trials would be determined entirely by what follows them on test trials where $p\left(\right.$ food $\left./ S^{r}+\right)=p\left(\right.$ food $\left./ S^{r}-\right)=.5$. On the other hand, with $30-\sec S^{r}$, the STM cues during the latter part of $S^{r}$ on test trials would no longer be discriminably different from the cues during the latter part of $S^{r}$ on training trials. The common cue pattern just before termination of $S^{r}$ on the two types of trials would assure that the differential conditioned reinforcing value acquired by $S^{r}+$ and $S^{r}$ - on training trials would be effective on test trials. Note that the question of whether or not the birds discriminate between the first portion of $S^{r}$ s on training and test trials is irrelevant. So long as the pattern of cues during the last instant of $S^{\mathbf{T}}$ on test trials is not discriminated from the last instant of $S^{r}$ on training trials, differential conditioned reinforcing value acquired on training trials should generalize to test trials. In this case, the proportion of the time a stimulus is followed by food on all trials determines the strength of its conditioned reinforcing effect. During Phases 1 and 2 of our experiment, $\mathrm{p}\left(\right.$ food $\left./ \mathrm{S}^{\mathrm{r}}+\right)=.7(18 / 20$ train, $5 / 10$ choice, and $5 / 10$ forced trials $)$ and $p\left(\right.$ food $\left./ S^{r}-\right)=.3$. Thus, $S^{r}+$ and $S^{r}$ - provided differential reinforcement on test trials for Groups 10 and 30 but not for Group 3.

Examination of Figures 2 and 3 also shows a suggestive, but nonsignificant, tendency for Group 10 to acquire a preference for $S^{r}+$ faster than Group 30 during Phase 1 . On the other hand, there is a tendency for at least two of the Group 10 subjects (T14 and R100) to be the slowest to reverse their choice during Phase 2. Those Group 10 birds may have begun to discriminate the cue pattern just before offset of $S^{r}$ on test trials from the cue pattern just before $S^{r}$ offset on training trials during Phase 2.

This explanation of the effects of the duration of $S^{r}$ on its differential reinforcing effect is from within a conceptual framework in which it is assumed that all causation is temporally contiguous. More specifically, we assumed that steady-state choice responses were determined by the relative (conditioned) reinforcing value of the set of conditions that immediately followed the alternative choice responses. Two other explanations have been derived from a conceptual framework in which it is assumed that cause and effect need not be temporally contiguous. One such explanation (e.g., Williams \& Fantino, 1978) is based on the assumption that $S^{\mathbf{r}}$ will continue to have a direct delayed reinforcing effect for more than $3 \mathrm{sec}$ after the choice response. In this case, the Group 30 birds would receive direct differential reinforcement during at least a part of the interval between 3 and $30 \mathrm{sec}$ after the choice response. The Group 3 birds would not be differentially reinforced during this interval. The other explanation is that, because of a delay gradient of direct primary reinforcement, the food delivered on half the test trials masked the differential conditioned reinforcing effects of $S^{\Upsilon}+$ and $S^{\Upsilon}-$ more in the case of Group 3. The food would have less of a masking effect when the interval between response and reward was $30 \mathrm{sec}$ long. In this case too, the briefer $S^{r}$ is on test trials, the less the differential reinforcing effects of $S^{r}+$ and $S^{r}-$.

The absence of a reliable difference in rate of (auto) pecking to $S^{r}+$ and $S^{r}-$ is similar to Perkins et al. 's (1975) finding that with 8-sec stimuli, rate of steady state autoshaped keypecking was about the same with $11 \%$ and $100 \%$ reinforcement. The negative relationship between stimulus duration and rate of autoshaped keypecks has also been obtained by Perkins et al. and Gibbon, Baldock, Locurto, Gold, and Terrace (1977).

Taken in conjunction with the greater choice of $S^{r}+$ than of $S^{\mathbf{r}}$ - for Groups 10 and 30 , the absence of any differential rate of autopecking to $S^{r}+$ and $S^{r}$ - seems to indicate that rate of autopecking is not a suitable index of the conditioned reinforcing value of stimuli localized on response keys. As Hancock (1982) has pointed out, there is much other evidence indicating that the conditioned reinforcing value of a stimulus that evokes a conditioned response is not always a monotonic function of the "strength" of the conditioned response. Nevertheless, our results provide direct evidence that the conditioned reinforcing value of a stimulus localized on the response key is not always positively correlated with the rate of autoshaped keypecking.

\section{EXPERIMENT 2}

Experiment 2 was designed to provide a test between the implications of our interpretation of the results of $\mathrm{Ex}$ periment 1 in terms of discrimination between training and test trials and the other two interpretations described above. There were four groups, one with each combination of 3- or 30-sec durations of $S^{r}$ on training and test trials in a simple $2 \times 2$ design. The groups were designated 3-3, 3-30, 30-3, and 30-30, where the first number represents $S^{r}$ duration on training trials and the second number designates $S^{r}$ duration on test trials. Otherwise, the procedures of Experiments 1 and 2 were similar.

According to our discrimination hypothesis, only Group 30-30 should acquire a clear preference for the choice response followed by $S^{r}+$. So long as $S^{r}$ lasts only $3 \mathrm{sec}$ on either training or test trials, any pattern of cues during this 3-sec interval on one type of trial will be discriminated from any pattern of cues occurring during $S^{r}$ on the other type of trial. Therefore, only what follows $S^{r}+$ and $S^{r}-$ on 3 -sec test trials will affect their conditioned reinforcing value on test trials. Because $\mathbf{S}^{\mathbf{r}}+$ and $\mathbf{S}^{\mathbf{r}}-$ are each followed by food on $50 \%$ of the test trials, they will 
have equal conditioned reinforcing value if their duration does not exceed $3 \mathrm{sec}$. If the duration of $S^{\mathrm{r}}$ on training trials is $3 \mathrm{sec}$, then, on these trials, $S^{\mathrm{T}}$ will include distinctive STM cues which will be absent on test trials. As a result, training trials with $3-\sec S^{\mathrm{r}} \mathrm{s}$ will not affect the differential conditioned reinforcing value of $S^{r}+$ and $S^{r}-$ on test trials, no matter what the duration of $S^{r}$ on test trials.

On the other hand, each of the interpretations that is based on the assumption that events that follow the choice response by $3 \mathrm{sec}$ or more have a direct reinforcing effect on the choice responses implies that the longer $S^{\mathrm{T}}$ is on test trials, the greater the preference for the response followed by $S^{r}+$ will be. For both Groups 3-30 and 3030 a direct delayed conditioned reinforcing effect would continue between 3 and $30 \mathrm{sec}$ after choice and provide greater differential conditioned reinforcement with $30-\mathrm{sec}$ than with 3-sec $S^{r}$ s. Similarly, if delayed primary reward delivered on half the test trials attenuates the differential conditioned reinforcing effect, this effect should be greater when $S^{\mathrm{r}}$ is delayed only $3 \sec$ (as with $3-\sec \mathbf{S}^{\mathrm{T}} \mathrm{S}$ ) than when it is delayed $30 \mathrm{sec}$. Either or both of these effects would lead to faster acquisition of a preference for the choice followed by $S^{r}+$ with $30-\sec S^{r}$ on test trials, no matter what the duration of $S^{r} S$ on training trials.

\section{Method}

Subjects. The subjects were eight naive pigeons randomly assigned to four groups of two. Both birds and housing were as described for Experiment 1.

Apparatus. The experimental chambers were the same as for Experiment 1 except that the houselight was a 6-W lamp in the center of the ceiling of the chamber.

Procedure. Preliminary training was the same as in Experiment 1. The procedures for the four groups differed only in the duration of $\mathbf{S}^{\mathbf{r}}+$ and $\mathbf{S}^{\mathbf{r}}-$, which was the same on training and test trials at 3 and $30 \mathrm{sec}$ for Groups 3-3 and 30-30, respectively. These two groups were a replication of Experiment 1, except that horizontal and vertical stripes were the choice stimuli and position was randomized. For Group 3-30, the duration of $S^{T} \mathbf{s}$ was $3 \mathrm{sec}$ on training trials and $30 \mathrm{sec}$ on test trials. The durations were reversed for Group 30-3. The choice trials may be considered a simultaneous discrimination learning procedure with $S^{\mathbf{T}}+$ (red keylight) following pecks to one stimulus (e.g., horizontal) and $S^{r}-$ (green) following pecks to the other. The horizontal stimulus appeared equally often on the right and left keys on the 40 training trials, the choice trials, and the 10 forced trials of each session. The horizontal-vertical choice procedure was employed to eliminate any possible bias from side preferences. In other respects, training sessions were as in Experiment 2 .

Phase 2 differed from Phase 1 only in that the relation between the horizontal and vertical choice stimuli and the red and green $S^{r} s$ that followed was reversed between phases. For example, if the sequences had been horizontal-red and vertical-green in Phase 1, they were horizontal-green and vertical-red in Phase 2.

Before initiation of the experiment, criteria were established for switching the subject to Phase 2 . All subjects received at least 15 sessions of Phase 1 . Subsequently, there were two criteria for switching from Phase 1 to Phase 2 on the next session. The strong criterion was choice of either the horizontal or the vertical stimulus at least $90 \%$ of the time on each of three consecutive sessions. The moderate criterion was choice of the same stimulus on at least $70 \%$ of the choice trials on each of Sessions 30-35. If, after 15 sessions, a pigeon met a criterion of no preference, which was choice of neither horizontal nor vertical on over $70 \%$ of the choice trials for five successive sessions, its training was terminated without any Phase 2 training. After 15 sessions, Phase 2 training was terminated as soon as one of the above criteria (strong preference, moderate preference, or no preference) had been met.

\section{Results and Discussion}

The percent of the time the response followed by $S^{r}+$ was chosen during successive pairs of training sessions is plotted for individual pigeons in Figure 5. As can be seen there, none of the subjects in any group with 3-sec $S^{\mathrm{T}} \mathrm{s}$ on either training or test trials showed a clear enough preference to meet the criterion for initiation of Phase 2. In fact, all but one of the six subjects in these groups met the no-preference criterion (no more than 7 of the 10 choice responses to the same stimulus on five successive sessions). The other subject (59 in Group 3-3) averaged 7 of 10 choices of $S^{\mathrm{T}}+$ on Session 31-35 and showed an overall trend towards indifference during the last 20 sessions. Thus, Groups 3-3, 3-30, and 30-3 showed no clear systematic deviation from equal choice of the two keys.

The two pigeons in Group 30-30 each acquired a strong enough preference for the choice followed by $S^{r}+$ to be reversed. Pigeon 22 met the strong criterion on Session 30 of Phase 1 . Pigeon 70 met the moderate criterion for preference. In Phase 2, both Group 30-30 birds reached the strong criterion by acquiring a preference for the stimulus that was followed by $S^{\mathbf{T}}+$. Because they reversed the stimulus chosen, their performance could not be at-

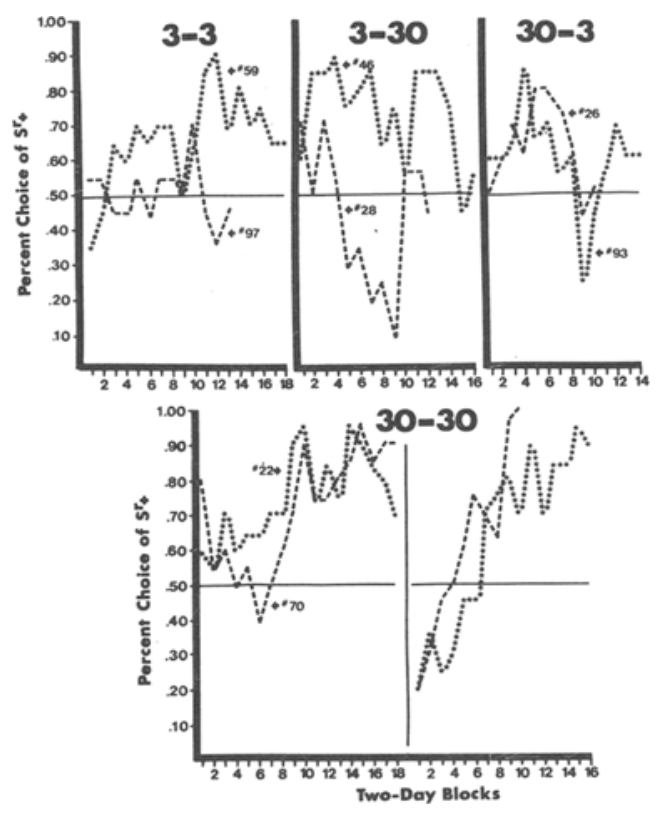

Figure 5. Percent choice of the stimulus (horizontal or vertical) preceding $\mathbf{S}^{\mathbf{r}}+$ on test trials in Experiment 2 for individual pigeons on successive pairs of sessions. Reversal (Phase 2) training was given only to pigeons in Group 30-30, because other subjects failed to reach a criterion for reversal. 
tributed to a preprogrammed preference for horizontal or vertical.

The difference between the choice performance of Group 30-30 and the other birds is striking. At the same time, the individual differences within Group 30-30 and within the other three groups combined are relatively small and unsystematic. Therefore, the results of Experiment 2 should not be dismissed because of the small Ns.

The results of Experiment 2 are just what is to be expected if, in a learning-tests procedure, conditioned reinforcement is effective on test trials only when $S^{r}$ is long enough on both training and test trials to preclude differential STM cues on the two types of trials just before termination of $S^{r}$. Furthermore, the results are consistent with the assumption that conditioned reinforcing properties are context specific, STMs are a part of the context, and the STMs persisted for more than 3 but less than $30 \mathrm{sec}$. The results are contrary to the implication of either of the alternative views described above.

\section{GENERAL DISCUSSION}

Our results failed to indicate any conditioned reinforcing effect of stimuli on test trials if they had been brief on either training or test trials. Just how much this finding can be generalized can be determined only by further experimentation. However, on theoretical grounds, it seems probable that it will hold across species and with many procedural variations within learning-tests procedures. The minimum duration required probably differs across species and with many variations in procedure. In any case, it seems clear that if one wishes to provide clear evidence of conditioned reinforcement by a learning test, the stimuli that are to serve as conditioned reinforcers should not be brief.

The expression "conditioned reinforcement" seems to have been used to designate at least two concepts which, though related, are clearly different. For example, some writers (e.g., Lawrence \& Hommel, 1961; Williams \& Fantino, 1978) have assumed that conditioned reinforcement is an attribute of a component stimulus and independent of context. Others (Cronin, 1980; Perkins, 1983; Spence, 1947; Winter \& Perkins, 1982) have assumed that it is a property of the entire pattern of cues. As we have already noted, some (Perkins, 1983; Powell \& Perkins, 1957; Spence, 1947) assume that a reinforcer, whether primary or conditioned, reinforces only immediately antecedent responses, but others (e.g., Williams \& Fantino, 1978) assume that there is direct delayed reinforcement. These points of disagreement are not all unrelated. The assumption that there is no direct delayed reinforcement seems to always be accompanied by the assumption that conditioned reinforcing value is an attribute of patterns of cues rather than of component stimuli.

The tendency in Experiment 1 for Group 10 to acquire the initial preference faster than Group 30 is in line with Fantino's (1977) delay reduction hypothesis and similar notions, according to which differential conditioned re- inforcing properties are a negative function of the delay between stimulus onset and the primary reward or nonreward. This relationship should hold whenever the duration of the stimuli is great enough so that the subject fails to discriminate the conditions just before termination of $S^{T}$ on training trials from conditions just before termination of $S^{r}$ on test trials. As indicated by the difference between the reinforcing effects of the 3- and 10-sec stimuli, when the stimuli are brief, there is a positive relationship between stimulus duration and the differential conditioned reinforcing value acquired by the stimuli in a learning-tests procedure. Thus, the expected overall relationship between $S^{r}$ duration and differential conditioned reinforcing value is an inverted $\mathrm{U}$-shaped function. $\mathrm{Be}$ cause generalization from training to test trials should decrease as the discrimination between training and test trials increases with training, the maximum of the inverted $\mathrm{U}$-shaped function should shift to the right as training increases.

The general paradigm we have studied is one in which the same stimulus (X2) occurs within two different sequences of events (XA1 1 X2 $-\mathrm{XA} 3$ and $\mathrm{XB} 1 \rightarrow$ $\mathrm{X} 2 \rightarrow \mathrm{XB} 3$ ) and the events that follow $\mathrm{X} 2$ in the two sequences (XA3 and $\mathrm{XB} 3$ ) differ in reinforcing value. The relationships involved in this paradigm are important in part because this paradigm, which is explicit in a learningtests investigation of conditioned reinforcement, is implicit in several other procedures. Among them are those investigations of delayed reward learning in which the same environmental stimuli are present during the interval between the correct choice response and reward, and the interval between the alternate choice and nonreward. Delay of reward gradients obtained with this procedure are steeper than those obtained when different environmental stimuli are present during the delay interval on rewarded and nonrewarded trials (Cronin, 1980; Grice, 1948; Perkins, 1947). It appears that when the delay is very brief, the STM cues on rewarded and nonrewarded trials acquire differential conditioned reinforcing value as effectively as differential environmental stimuli. However, as the delay increases, the STM cues will become more and more difficult to discriminate. Therefore, the delay of reward (or punishment) gradient will be steeper when the environmental stimuli that fill the delay interval are the same on rewarded and nonrewarded trials.

The procedures employed by Winter and Perkins (1982) and by Cronin for her reinstatement and reversed cue groups also incorporate the basic paradigm, as do some of the procedures involving presentation of brief stimuli in compound schedules (see Gollub, 1977, for a review). The paradigm may also be applied to conditions in which there is no change in environmental stimuli with the transition from X2 to XA3, and this stimulus situation lasts longer in the $\mathrm{XA} 1 \rightarrow \mathrm{X} 2-\mathrm{XA} 3$ sequence than in the $\mathrm{XB} 1 \rightarrow \mathrm{X} 2 \rightarrow \mathrm{XB} 3$ sequence. In this case, if $\mathrm{X} 2$ and $\mathrm{XA} 3$ are both the availability of food, the paradigm may be applied to the effects of the duration of a primary reward on the reinforcing value of its delivery. Powell and Per- 
kins (1957) found that the reinforcing effect of a food delivery did not depend on the duration of the availability of food on the trial on which the food followed the response it reinforced, but did depend on the mean length of time food had been available on previous occasions in that same context. It appears that, at least in this case, the total reinforcing effect of the introduction of a "primary reward" was largely determined by differential conditioned reinforcing value derived from continued presence versus absence of the reward.

This analysis of our results and related findings suggests that conditioned reinforcing value is an attribute of patterns of cues rather than of component stimuli. It also seems to imply that delayed rewards have a reinforcing effect only when the pattern of cues that immediately follows the rewarded response acquires greater conditioned reinforcing value than the cue pattern that follows other behavior. These assumptions are sufficiently different from some treatments of conditioned reinforcement that one of us (Perkins, 1983) found it advisable to describe the processes involved in other terms which are less likely to carry connotations that are both unintended and outdated.

\section{REFERENCES}

Cronin, P. B. (1980). Reinstatement of postresponse stimuli prior to reward in delayed-reward discrimination learning by pigeons. Animal Learning \& Behavior, $8,352-358$.

Fantino, E. (1977). Conditioned reinforcement: Choice and information. In W. K. Honig \& J. E. R. Staddon (Eds.), Handbook of operant behavior. Englewood Cliffs, NJ: Prentice-Hall.

Gibbon, J., Baldock, M. D., Locurto, C., Gold, L., \& Terrace, H. S. (1977). Trial and intertrial durations in autoshaping. Journal of Experimental Psychology: Animal Behavior Processes, 3, 264-284.

GolluB, L. (1977). Conditioned reinforcement: Schedule effects. In W. W. Honig \& J. E. R. Staddon (Eds.), Handbook of operant behavior. Englewood Cliffs, NJ: Prentice-Hall.
Grant, D. S., \& Roberts, W. A. (1976). Sources of retroactive inh1bition in pigeon short-term memory. Journal of Experimental Psychology: Animal Behavior Processes, 2, 1-16.

GricE, G. R. (1948). The relation of secondary reinforcement to delayed reward in visual discrimination learning. Journal of Experimental Psychology, 38, 1-16.

Hancock, R. A. (1982). Tests of the conditioned reinforcing value of sequential stimuli in pigeons. Animal Learning \& Behavior, 10, 46-54.

LAWRENCE, D. H., \& HOMMEL, L. (1961). The influence of differential goal boxes on discrimination learning involving delay of reinforcement. Journal of Comparative and Physiological Psychology, 54, 552-555.

MAKI, W. S. JR., MoE, J. C., \& Bierley, C. M. (1977). Short-term memory for stimuli, responses, and reinforcers. Joumal of Experimental Psychology: Animal Behavior Processes, 3, 156-177.

Perkins, C. C. (1947). The relation of secondary reward to gradients of reinforcement. Journal of Experimental Psychology, 37, 377-393.

Perkins, C. C. (1983). The analysis of performance. In M. D. Zeiler \& P. Harzem (Eds.), Advances in analysis of behavior: Vol. 3. Biological factors in learning. Chichester: Wiley.

Perkins, C. C., Beavers, W. O., Hancock, R. A., Hemmendinger, P. C., Hemmendinger, D., \& Ricci, J. A. (1975). Some variables affecting rate of key pecking during response-independent procedures (autoshaping). Journal of the Experimental Analysis of Behavior, 24, 59-72.

Powell, D. R., \& PERKINS, C. C. (1957). Strength of secondary reinforcement as a determiner of the effects of duration of goal response on learning. Journal of Experimental Psychology, 53, 106-112.

SPENCE, K. W. (1947). The role of secondary reinforcement in delayed reward learning. Psychological Review, 54, 1-8.

WIKE, E. L. (1966). Secondary reinforcement: Selected experiments. New York: Harper and Row.

Williams, B. A., \& Fantino, E. (1978). Effects on choice of reinforcement delay and conditioned reinforcement. Journal of the Experimental Analysis of Behavior, 29, 77-86.

Winter, J., \& Perkins, C. C. (1982). Immediate reinforcement in delayed reward learning in pigeons. Journal of the Experimental Analysis of Behavior, 38, 169-179.

(Manuscript received September 5, 1983; revision accepted for publication February 3, 1984.) 